\title{
Los cuerpos que somos y pensamos. Críticas de Judith Butler al escepticismo cartesiano y al constructivismo contemporáneo y aclaraciones sobre su comprensión de la existencia humana
} Being Bodies, Thinking Bodies. Judith Butler's Critiques to the Cartesian Scepticism and Contemporary Constructivism and Some Clarifications about her Understanding of Human Existence

\author{
ISABEL G. GAMERO CABRERA* \\ IDIHCS del CONICET/Universidad de La Plata (Argentina)
}

\begin{abstract}
RESUMEN. En este artículo analizo las críticas recientes de Judith Butler al escepticismo cartesiano y al constructivismo posmoderno (identificado con las obras de Preciado y Haraway), para explicar el distanciamiento de Butler respecto de posturas constructivistas y, al mismo tiempo, como un argumento para afirmar la dimensión ética y con pretensión de universalidad de su defensa de las vidas precarias.
\end{abstract}

Palabras clave: escepticismo; constructivismo; duda hiperbólica; vidas precarias.
ABSTRACT. In this paper, I analyse Judith Butler's recent critics against the Cartesian scepticism and the posTmodern constructivism (indentified by Preciado and Haraway's works), in order to explain Butler's distance from constructivism and, at the same time, to assert the ethical and potentially universal dimension of her defence of the precarious lives.

Key words: scepticism; constructivism; hyperbolic doubt; precarious lives.

\footnotetext{
*ig.gamero@filos.ucm.es ORCID iD:http://orcid.org/ 0000-0002-6216-7119. 


\section{PRESENTACIÓN: ACLARACIÓN CONCEPTUAL Y CONTEXTUALIZACIÓN ${ }^{1}$}

\section{(1) Escepticismo}

Según la Enciclopedia Stanford de Filosofía ${ }^{2}$, el escepticismo filosófico es la corriente que duda de la realidad o posibilidad de conocimiento de un conjunto de proposiciones o creencias. Se pueden distinguir dos tipos: el radical (que duda de todos los conjuntos de proposiciones o creencias y aduce que nada se puede conocer) y el moderado (que presenta una duda más restringida, sólo aplicada a ciertos conjuntos de proposiciones; no afirma que no se pueda conocer nada, sino que nos faltan certezas y plantea cuestiones sobre la validez o justificación del conocimiento).

El principal ejemplo de escepticismo que trataré es la duda hiperbólica de la primera meditación cartesiana y su argumento del sueño; lo he elegido por ser el que recibe las críticas directas de Butler que serán analizadas en este artículo. No se trata, sin embargo, de un tema del siglo XVII, autores contemporáneos como Barry Stroud (1985) o Peter Unger (1993) siguen aduciendo la actualidad y viabilidad de esta duda. Por ejemplo, para Stroud, Descartes establece el origen y las garantías del conocimiento en los sentidos (1985:6), lo que abre una brecha entre las impresiones sensoriales recibidas y la realidad (los fenómenos y el noúmeno, expresado en términos kantianos). Esta brecha provoca desconfianza en el conocimiento y facilita la formulación de la duda escéptica, porque reconocemos que los sentidos nos han engañado antes y que las experiencias sensoriales que recibimos despiertos son indistinguibles de las soñadas (Stroud, 1985: 31-32, Descartes, 2005: 82).

Me interesa destacar, como hace Stroud con insistencia (1985:13), que ésta es una argumentación en el terreno de las posibilidades, no en el de los hechos. Ni Descartes ni Stroud afirman que estamos de hecho dormidos y que no podamos conocer; sino que en el caso de que lo estuviéramos, no podríamos saberlo, por lo que nuestro conocimiento no está libre de dudas. En este sentido, quienes tratan de superar la duda escéptica manteniendo que, en ocasiones, conocemos cosas y sabemos que no estamos soñando, no llegan a refutar el ar-

${ }^{1}$ En consonancia con una conclusión de este artículo (no hay nadie separado o independiente de los demás) quiero agradecer a quienes me ayudaron durante el proceso de redacción: a J.G., en cuya casa comencé a escribirlo y cuya biblioteca usé con profusión; a toda la familia C.P., en cuya casa logré la tranquilidad necesaria para acabarlo; a F.J.B., quien me ayudó a aclarar el término "paralepsis" y a A.M.C. quien se leyó la primera versión, me dio buenas ideas para el cierre y me aconsejó dónde y cómo cortar. Sin estas personas, este artículo no hubiera sido posible.

${ }^{2}$ Klein, Peter, "Skepticism", The Stanford Encyclopedia of Philosophy (Summer 2015 Edition), Edward N. Zalta (ed.) http://plato.stanford.edu/archives/sum2015/entries/skepticism 
gumento cartesiano ${ }^{3}$ (Stroud, 1985:34). Es decir, la duda cartesiana no niega el conocimiento del mundo exterior ni dice que no se pueda conocer nada (esto sería un ejemplo de escepticismo radical, fácil de objetar), sino que intenta mostrar que aquello que dábamos por sentado (la fiabilidad del conocimiento empírico) no es tan fiable como pensábamos, ya que podríamos estar alucinando o dormidos sin saberlo4. (Stroud, 1985:18).

Por último, esta duda también se extiende a otras personas, es decir, si dudamos de que podemos conocer lo que sucede a nuestro alrededor, ¿cómo saber si no soñamos también a la gente que nos rodea? Ésta es la reflexión que mantiene Descartes cuando ve personas a través de su ventana y se preguntar si son imaginaciones o ensoñaciones suyas, "capas y sombreros que podrían cubrir máquinas artificiales movidas por resortes" (Descartes, 2005:97, Stroud, 1985:38).

También me voy a referir a otro argumento escéptico más reciente para facilitar la exposición. Se trata de la posibilidad de que el conocimiento esté vedado por un malvado científico que nos ha encerrado en su laboratorio y conectado a una máquina de realidad virtual. Lo que creíamos conocer no son más que simulaciones virtuales que este científico transmite a nuestro cerebro; mientras que nuestro cuerpo, existente y real, permanece en el laboratorio. Este argumento apareció por primera vez en la literatura de ficción en "The Affair of the Brains" de Anthony Gilmore (1932) y el primer filósofo que lo teorizó fue Gilbert Harman quien contempló la posibilidad de que tras un accidente de coche lo único que quedara del superviviente fuera su cerebro, que es mantenido con vida en un laboratorio, conectado a un ordenador 5 . Harman se pregunta cómo (o si) esta persona podría llegar a saber que es un cerebro conectado a una máquina y concluye que si en realidad estuviera en esta situación no podría saberlo (1973:5). Más adelante, el argumento fue popularizado con la conocida crítica de Putnam quien sostuvo que si nuestros cerebros estuvieran en realidad en una cubeta, los términos "cerebro" y "cubeta", en la frase "soy un cerebro en una cubeta", tendrían una referencia distinta a la que el supuesto cerebro cree, por lo que esta frase sería falsa

${ }^{3}$ En el primer capítulo de The Significance of Philosophical Scepticism, Stroud da una explicación muy clara del argumento escéptico cartesiano; en ella no menciona explícitamente a ningún autor que rechace el escepticismo, únicamente mantiene que constatar el hecho de que alguien conoce algo no es una respuesta o solución al desafío escéptico, sino que tan sólo supone dejar de lado la cuestión del escepticismo sobre el mundo exterior, sin llegar a profundizar en su contenido (1985:34). Más adelante en esta misma obra, Stroud discutirá con autores críticos con el escepticismo como Michael Williams (cuyos argumentos trataré más adelante), George E. Moore y Ernest Sosa.

${ }^{4}$ Una ilustración ficticia, pero aclaradora, de esta dificultad es la película "Origen" (Nolan, 2010).

${ }^{5}$ Una trama similar ha sido desarrollada en el cine en "Código Fuente" (Duncan Jones, 2011). 
o incorrecta (1981:15). A diferencia de Putnam, autores como Moravec (1999) y Bostrom (2003) siguen manteniendo la validez de este argumento, sobre todo en el ámbito de la realidad virtual ${ }^{6}$. Por ejemplo, Bostrom destaca la gran dificultad técnica y gasto de energía que supondría el simulacro completo de la realidad en un mundo virtual ${ }^{7}$, pero argumenta que si esto fuera real y los humanos siempre hubiésemos estado en un mundo virtual no podríamos saberlo, ni salir de él sin intervención externa ${ }^{8}$ (2003:255).

En resumen, los argumentos escépticos explicados son hipótesis o posibilidades (lógicas antes que reales) que problematizan la fiabilidad del conocimiento empírico. No aducen que estemos soñando cuando creemos estar despiertos o que seamos cerebros en cubetas; sino que si aceptamos, como hizo Descartes, que el conocimiento proviene de los sentidos, entonces no podemos estar seguros de saber si estamos dormidos o engañados. Los contenidos sensoriales recibidos, fuentes del conocimiento, son compatibles con la posibilidad de que estemos dormidos y creamos que conocemos o con un mundo virtual. No habría prueba para demostrar la falsedad de estas hipótesis, ya que también podríamos estar soñando que hacemos esa prueba que no puede mostrar su propia fiabilidad (Stroud, 1985:22).

\section{(2) Constructivismo}

La Enciclopedia Stanford de Filosofía ${ }^{9}$ opone el constructivismo al realismo científico, ya que esta corriente no admite que el conocimiento se origine en una realidad externa, referente de nuestras emisiones, a partir de la cual se pueda corroborar la verdad o falsedad de nuestros enunciados. El constructivismo entiende la formación de conocimiento como un proceso contingente y modificable por factores sociales o humanos, como el punto de vista desde el que se

${ }^{6}$ Quisiera destacar que estos debates no pertenecen exclusivamente al ámbito de la filosofía sino que también han sido tenidos en cuenta por científicos contemporáneos, informáticos y expertos en realidad virtual. Véase por ejemplo http://www.bbc.com/earth/story/20160901-wemight-live-in-a-computer-program-but-it-may-not-matter.

${ }^{7}$ No hay que olvidar el ingente coste económico de los dispositivos de simulación de realidad virtual. Baste un ejemplo: todos los aparatos necesarios para el funcionamiento de la gama más baja de gafas de realidad virtual Oculus (que acaban de aparecer en el mercado, propiedad de Facebook) tienen un coste de unos 700 dólares, a lo que habría que sumarle cada uno de los juegos o aplicaciones que se pueden usar con estos dispositivos. Fuente: http://www.lavanguardia.com/tecnologia/20160106/301232155836/precio-fecha-oculus-rift.html-

${ }^{8}$ Un ejemplo ficticio de esta posibilidad es el de Neo en "Matrix" (Wachowski, 1999) que nunca hubiera sabido que vivía en un mundo recreado por máquinas si Morpheus no lo hubiera despertado y sacado de la vaina donde reposaba.

${ }^{9}$ Chakravartty, Anjan, "Scientific Realism", The Stanford Encyclopedia of Philosophy (Fall 2015 Edition), Edward N. Zalta (ed.) http://plato.stanford.edu/archives/fall2015/entries/scientific-realism/ 
teorice o los distintos usos lingüísticos que se den. Entre los primeros defensores de esta corriente se encuentran Feyerabend y Lakatos, así como los sociólogos Bergen y Luckman y, más recientemente, Ian Hacking.

Esta Enciclopedia también dedica un epígrafe al constructivismo feminista que cuestiona conceptos como "verdad" u "objetividad", al sostener que los procesos de formación del conocimiento han estado protagonizados por varones (sobre todo blancos y occidentales) que totalizan y universalizan su forma de conocer y minusvaloran el punto de vista de las mujeres (y de personas de otras razas y culturas, cabría añadir). Estas autoras, entre las que se encuentran Haraway y Preciado ${ }^{10}$, critican toda concepción objetiva y universal del conocimiento y dan como alternativa versiones contingentes y subjetivas, donde la realidad o los cuerpos no son independientes del modo como se comprendan, describan o teoricen.

\section{(3) Contextualización}

Una vez definidos los términos, quisiera responder a unas preguntas que quizás quien me lea ya se ha hecho: ¿qué tienen que ver estos argumentos escépticos con Judith Butler?, ¿acaso esta autora no es una pensadora posmoderna y queer que entiende los cuerpos como construidos y construibles?

Como respuesta, ofrezco este artículo donde desarrollo la crítica que Butler dirige al escepticismo cartesiano y al constructivismo posmoderno ${ }^{11}$ en Los sentidos del sujeto (2015). A partir de ahí, intentaré aclarar su postura sobre la existencia humana, que entiendo como realista (moderada) y como universalista (al menos potencialmente) dada su defensa de las vidas precarias.

Esta comprensión de la teoría de Butler puede resultar novedosa, o incluso sorprendente, para quien identifique las tesis de esta autora con planteamientos posmodernos o constructivistas, donde se diluyen o desdibujan los cuerpos en aras de una libertad de opciones sexuales; ya sea para criticar ese constructivismo como hacen Benhabib ${ }^{12}$ (1992, 1995), Nussbaum (1999) o Boucher (2006); o para

${ }^{10}$ Me referiré a los argumentos de Haraway y Preciado a lo largo de este artículo, por ello no describo su teoría aquí.

${ }^{11}$ Entiendo que constructivismo y posmodernismo son posiciones distintas, si las igualo aquí es porque sigo a Butler, quien en otra muestra de sus intentos de superar debates filosóficos y lingüísticos abstractos, para centrarse en temas éticos y políticos, declara no estar tan preocupada por los términos que se usan, sino por las tensiones y consecuencias que suceden cuando su propuesta se vincula a la deconstrucción (2015:34)

${ }^{12}$ Esta crítica de Benhabib a Butler es matizable. Si bien Benhabib dirigió críticas a Butler por su constructivismo, tanto en El ser y el otro en la ética contemporánea, como en el debate que ambas establecieron en 1990 (publicado en Feminist Contentions), en sus obras más recientes estas dos autoras han acercado sus posturas al interesarse más por las personas en situación de exclusión o riesgo y menos por debates teóricos y terminológicos. 
defenderlo, elogiarlo y enarbolarlo, como hacen Soley Beltrán y Sabsay (2012), Pérez Navarro (2008) o Preciado (2011). Sin embargo, una lectura más atenta a la obra de Butler muestra que su supuesto constructivismo está compensado por el reconocimiento de la vulnerabilidad y dañabilidad de las vidas precarias que son, en definitiva, todas las vidas humanas (2010:71).

Quisiera argumentar que esta preocupación ya estaba presente en las primeras obras de Butler ${ }^{13}$, al modo de un caveat respecto de algunas tendencias del feminismo que limitan el significado de los géneros a unas prácticas normalizadas y habituales, lo que puede tener consecuencias excluyentes, e incluso homófobas, para muchas personas que viven en una sociedad que no reconoce su forma de ser, por lo que su existencia se torna "imposible, ilegible, irrealizable, irreal e ilegítima" (1990:8). Butler va extendiendo esta preocupación a otros colectivos y sensibilidades, no necesariamente identificados con la orientación sexual, y a partir de ahí surge su concepto de "vida precaria".

Una vez contextualizadas las motivaciones que llevan a Butler a escribir y el lugar donde se sitúa para enunciar su crítica, sólo queda destacar que en Los sentidos del sujeto la autora dirige varias objeciones al escepticismo cartesiano y las conecta con propuestas constructivistas de las que se distancia $(2015: 34)^{14}$. Entiendo las críticas de la autora en oposición al escepticismo como una respuesta a quienes la critican por ser constructivista y, al mismo tiempo, como un argumento para afirmar la dimensión ética, con pretensión de universalidad, de su propuesta.

\section{PRINCIPALES CRÍTICAS: LAS DOS ESCISIONES}

Butler critica el escepticismo cartesiano porque considera que Descartes lleva a cabo dos escisiones problemáticas que hay que diagnosticar y superar para dar lugar a una comprensión más clara del conocimiento y las relaciones humanas. Estas escisiones también aparecen en la obra de algunos autores constructivistas contemporáneos, a quienes también les dirigiré estas críticas.

${ }^{13}$ No considero que haya una ruptura en el pensamiento de Butler entre la propuesta performativa de sus primeras obras hasta la postura ética y política reciente. Por el contrario, encuentro una continuidad en su pensamiento y sus intentos de responder a las preguntas sobre cómo se puede reconocer a todos los humanos con sus diferencias y cómo evitar la discriminación de las personas que no cumplen los cánones (luego llamados "marcos") habituales de ser. Una buena obra donde se destaca y explica esta continuidad es Qué cuenta como una vida de Elvira Burgos.

${ }^{14}$ Butler se dirige sobre todo al escepticismo cartesiano y no alude a Haraway y Preciado, ni a ningún constructivista; pero encuentra paralelismos entre el escepticismo cartesiano y el constructivismo posmoderno (2015:34) y expresa su deseo de distanciarse (y de que la distancien) de los feminismos radicales y constructivistas que niegan el cuerpo (2015:31). Siguiendo esta línea, extenderé las críticas de Butler al escepticismo a las dos autoras ya citadas. 


\subsection{Primera escisión: lenguaje y mundo}

\subsubsection{Críticas de Butler}

La primera escisión que Butler critica del planteamiento cartesiano es la que separa, a la manera positivista, entre mente y mundo (res cogitans y res extensa) como si se tratara de dos ámbitos completamente diferentes, opuestos e inconmensurables; y que presupone, además, la existencia de un "reino ontológico" distinto de la existencia humana. Es por esta separación tan drástica que resulta más plausible la formulación de la duda escéptica sobre el mundo exterior (2015:34).

Esta crítica no es aportación exclusiva de Butler, aparece en numerosas ocasiones en el debate sobre el escepticismo. Por ejemplo, Michael Williams señala que el escepticismo cartesiano adquiere gran parte de su plausibilidad y poder persuasivo por mantener una concepción fundacionalista y empirista del conocimiento que presupone la existencia objetiva de la realidad exterior y que ésta se puede conocer "como un todo", de modo justificado, bien fundamentado y objetivo (1988:417-419). Esta concepción plantea, además, demandas de justificación muy exigentes e incluso artificiales, que no se pueden satisfacer con nuestro conocimiento cotidiano y falible, por lo que se abre una brecha entre estas exigencias y nuestro conocimiento y, justo ahí, triunfan los argumentos escépticos (1988:431-432). Por el contrario, si en vez de esta concepción del conocimiento se partiera de una más moderada, falible y contingente, que admita que los humanos tenemos limitaciones y erramos pero que, pese a todo, seguimos conociendo, los argumentos escépticos no serían tan plausibles (1988:427). Williams también critica que el ejemplo paradigmático que acaba favoreciendo la duda hiperbólica sea el de un hombre, solo en su habitación, que presupone la existencia separada y objetiva de la realidad exterior y trata de encontrar un argumento incuestionable para demostrarla. Por el contrario, continua Williams, el punto de partida de Descartes es un caso bastante poco habitual de conocimiento que no se debería generalizar, ni convertir en base teórica para formular la duda escéptica (1988:435).

Butler continúa esta crítica y la extiende al constructivismo, al argumentar que tanto el escepticismo cartesiano como los constructivismos (que ilustraré con ejemplos de Preciado y Haraway) mantienen, pese a sus diferencias, una concepción del conocimiento y de la realidad semejante a la del positivismo, según la cual hay una clara distinción entre sujetos y objetos (o entre mente y cuerpo) y la única forma en la que los primeros pueden conocer a los segundos es por medio de los sentidos (2015:34). Ahora bien, cuando los sentidos fallan, parece que se puede dudar de todo. Es decir, una vez se quiebra o pro- 
blematiza la concepción empirista del conocimiento, estos autores fortalecen el polo subjetivo y mental, lo que facilita tanto la formulación de la duda sobre el conocimiento del mundo (en el caso de Descartes) como la propuesta de deconstruir la realidad y los cuerpos (en el caso de los constructivistas) (Butler, 2015:37). A continuación, daré unas citas de las Meditaciones Metafísicas y del "Manifiesto Cíborg" para explicar estas dificultades:

(1) En primer lugar, Descartes, para poder llevar a cabo su duda metódica, se aísla de su exterior:

"He liberado a mi espíritu de toda clase de cuidados; hoy, que por dicha mía no me siento agitado por pasión alguna, y que me he procurado un reposo seguro en una apacible soledad, me aplicaré seriamente y con libertad a destruir en general todas mis antiguas opiniones" (2005:81-82).

Sólo entonces, en tranquilidad y soledad, puede proponer el argumento del sueño; pero sigue siendo él, en primera persona, quien mira objetos, recuerda y duda de su propia posibilidad de conocer:

“iParéceme ahora que es con ojos dormidos con los que miro este papel, que esta cabeza que yo muevo no está adormecida; que es con deseo y propósito deliberado como extiendo esta mano y la siento: lo que sucede en el sueño no parece tan claro ni tan distinto como todo esto. Pero, pensando en ello cuidadosamente, recuerdo haber sido engañado durmiendo por semejantes ilusiones; $y$ deteniéndome ante esta idea, veo tan manifiestamente que no hay indicios ciertos por los cuales se pueda distinguir claramente la vigilia del sueño que me espanto" (2005:83).

Y como es bien sabido, esto le lleva a dudar de la posibilidad de conocer el mundo exterior:

"Supongo, pues, que todas las cosas que veo son falsas; estoy persuadido de que nada de lo que mi mendaz memoria me presenta ha existido jamás; pienso que no tengo sentidos; creo que cuerpo, figura, extensión, movimiento y lugar son ficciones de mi espíritu. ¿Qué, pues, podrá estimarse como verdadero? Acaso sólo esto: que nada hay en el mundo" (2005:89).

(2) Por su parte, Haraway comprende la realidad social y política de los seres humanos como construida y ficticia:

"Las fronteras entre ciencia ficción y realidad social son una ilusión óptica" [...]."La realidad social son nuestras relaciones sociales vividas, nuestra construc- 
ción política más importante, un mundo cambiante de ficción" [Uno de los elementos más relevantes de esta ficción es] "la construcción liberadora que comenzó con los movimientos internacionales feministas que han construido la 'experiencia de las mujeres' y, asimismo, han destapado o descubierto este objeto colectivo crucial. Tal experiencia es una ficción y un hecho político de gran importancia. La liberación se basa en la construcción de la conciencia, de la comprensión imaginativa de la opresión" (2005:253).

Sin embargo, esta construcción de las conciencias no resulta suficiente porque el sujeto "mujer" y sus luchas se han quedado obsoletas y son sustituidas por un nuevo sujeto: el cíborg, que se define así:

"El cíborg es materia de ficción y experiencia viva que cambia lo que importa como experiencia de las mujeres a finales de este siglo" (2005:253).

En la época de la posmodernidad, son los cíborgs los únicos que pueden mostrar el carácter construido de lo real y abrir nuevas preguntas y líneas de cuestionamiento críticas. Según Haraway:

"Las estrategias postmodernistas, al igual que el mito del cíborg, subvierten miríadas de totalidades orgánicas (por ejemplo el poema, la cultura primitiva, el organismo biológico). La certeza de lo que cuenta como naturaleza [...] se halla socavada, ya probablemente sin remedio. La autorización trascendente de interpretación se ha perdido y, con ella, la base ontológica de la epistemología occidental" (2005:254).

Analizaré ahora estos fragmentos siguiendo las críticas de Butler para destacar que algunos autores constructivistas cometen un error similar al de la duda hiperbólica cartesiana al separar entre sujetos y objetos o entre lenguaje y realidad, y hacer primar el primer polo sobre el segundo.

En la primera cita, Descartes tiene que aislarse de su exterior y de todas sus preocupaciones para comenzar a dudar. Aun así, sigue manteniendo la concepción sensorial del conocimiento (intenta mirar, tocar el papel...). Pero como no puede distinguir si está dormido o despierto, comienza a dudar de si puede conocer el exterior con seguridad y admite que puede errar; pero no se pregunta cómo conocen otros sujetos ni si es un paso válido universalizar sus conclusiones particulares a todos los procesos de conocimiento. Por su parte, Haraway celebra la aparición de una nueva concepción (construida y ficcionalizada) de la realidad y los humanos. En la etapa posmoderna, los cíborgs se han liberado de la concepción tradicional del conocimiento y crean un nuevo modo de ser y de conocer. Es decir, la autora presupone que en la modernidad 
se aceptaba una epistemología vinculada con una ontología, según la cual el mundo exterior existía y los humanos lo podían conocer. A continuación, declara el final de esa etapa por el inicio de la posmodernidad, cuando se descubre el carácter construido de lo que se pensaba que era cierto y los seres humanos pasan a ser cíborgs que deconstruyen las totalidades orgánicas o las certezas de la naturaleza.

Estos ejercicios de escepticismo y duda son posibles porque estos autores presuponen que anteriormente había algo real e incuestionable (el conocimiento sensorial del mundo exterior, las bases ontológicas de la epistemología tradicional) que queda problematizado, al tiempo que se refuerza el polo subjetivo y lingüístico. Tanto el escepticismo cartesiano como el constructivismo otorgan, siguiendo con este argumento de Butler, un poder omnímodo a los seres humanos, su lenguaje y sus conceptos, lo que les permite tanto crear realidades al modo performativo, como dudar de ellas y hacerlas desaparecer (2015:37). En conclusión, Butler encuentra errores similares en estos dos planteamientos por el reduccionismo de esta escisión entre mente y mundo, por el fortalecimiento del polo subjetivo y mental sobre el objetivo y material, y por la unilateralidad y direccionalidad de las relaciones que se establecen entre estos ámbitos, según la cual, personas, individuales y separadas, se pueden distanciar y operar a su libre arbitrio sobre el mundo, utilizando el lenguaje, que es entendido como un "agente unilateral e inequívoco que opera sobre el objeto de construcción" (2015:34). Este reduccionismo también supone un enfrentamiento irreconciliable entre un monismo ontológico y un monismo lingüístico, donde se otorga excesivo poder al lenguaje y a los conceptos, en la literalización del tropo de la performatividad que parece borrar la realidad. Además, también es una muestra de voluntarismo que entiende a algunos sujetos (Descartes o el cíborg) como libres, separados y completamente independientes. Esto es, estos autores mantienen la fantasía de un sujeto que ha perdido (o quitado importancia) a los vínculos con el exterior, con los demás seres humanos y el mundo, sin tener apenas en cuenta las limitaciones y restricciones de la realidad, de los cuerpos o de las leyes de la física, cabría decir (2015:37).

\subsubsection{Propuesta alternativa de Butler: los quiasmos del sujeto}

Para cerrar esta primera crítica, quisiera destacar que la alternativa que da Butler a este modelo de conocimiento y esta separación de realidades no es postular que los sujetos no existen o que son construcciones del lenguaje, como han criticado Benhabib (1992:244ss.) y Nussbaum (1999). Por el contrario, Butler se distancia tanto del realismo positivista que afirma la individualidad e independencia de los humanos como de su reverso, el constructivismo, que pretende decons- 
truir o eliminar esta supuesta individualidad. En contraste con estas concepciones, Butler sostiene que existen dos polos interconectados en la formación de cada ser humano que se influyen mutua y constantemente (2005:33). Por un lado, están las redes, contextos o normas sociales en las que cada cual se ha formado y que son condición de posibilidad y de inteligibilidad de los sujetos, ya que nadie puede crecer al margen de la sociedad, sin lenguaje o normas. Por el otro lado, están las subjetividades humanas que, aunque reciban influencia de estas normas y contextos, no están predeterminada por ellas, sino que las personas podemos trascender, cuestionar y modificar estas normas y contextos, gracias a su capacidad de agencia y toma de decisiones (2005:18-19).

Esta tesis de Butler no es nueva ni exclusiva de sus obras más recientes, sino que ya estaba presente en sus primeros libros. Por ejemplo, en El género en disputa, argüía que "los campos de 'representación' lingüística y política definen previamente el criterio mediante el cual se originan los sujetos mismos". Como consecuencia, sólo se puede representar aquello que se puede reconocer como sujeto. En palabras de Butler: "deben cumplirse los requisitos para ser un sujeto antes de que pueda extenderse [su] representación" (1990:46). Es decir, esta autora destaca los campos de representación y las normas contextuales que permiten el reconocimiento de los sujetos, de tal modo que ciertas subjetividades (existentes y reales) no son reconocidas porque no cumplen los requisitos exigidos por esos campos. Ahora bien, con esto Butler no quiere decir que los humanos no existen, en un sentido ontológico, ni duda de ellos al modo escéptico; sino que indica que su comprensión misma como humanos resulta muy difícil, o incluso imposible, si no se adaptan o adecuan a lo regulado y normalizado por los marcos. Y exactamente por eso escribió El género en disputa, para desmontar esta forma de representación excluyente y permitir que más subjetividades distintas reciban reconocimiento $(1999: 8,52)$. No obstante, en este primer libro, la autora insistía en exceso en el polo normativo o contextual, que entendía como unas "estructuras jurídicas del lenguaje y de la política [que] crean el campo actual de poder" y que carecen de afuera o exterior. En consecuencia, debilitaba las posibilidades de acción de los sujetos que sólo podían plantear críticas e intentar subvertir estos marcos y estos conceptos de identidad, desde dentro (1999:53), con complejos actos performativos que podían resultar contradictorios. Esto es, ¿cómo subvertir o eliminar aquello que nos da identidad. sin perder el sentido de lo que somos? Si estamos tan determinados por los marcos, ¿cómo se pueden cambiar?

Por el reconocimiento de estas dificultades y las críticas recibidas, Butler va matizando su teoría y presta más atención a las posibilidades de acción de los humanos que permanecen en los márgenes. En este sentido, en Dar cuenta de sí mismo, explica los procesos de autoconstrucción o autorrealización, según 
los cuales cada persona, al nacer, se encuentra en un contexto determinado y es interpelada por unas matrices de normas que "no producen al sujeto como un efecto necesario", ni lo determinan completamente (2005:32). Esto no significa que los seres humanos tengan "plena libertad para ignorar la norma" o sus condiciones de partida, sino que se establece una lucha con las condiciones de la propia vida, donde cada cual trata de definirse en contraste con estas matrices, intentando separarse de ellas al mismo tiempo que depende, en gran medida, de ellas (2005:33). Es decir, para Butler no hay dos ámbitos separados (ser humano y mundo), nadie puede ser completamente independiente (como sostenía Descartes), ni completamente construido (como mantiene Haraway), sino que se da una interconexión y modelado mutuo entre estos ámbitos. Además, a diferencia de El género en disputa, en Dar cuenta de sí mismo esta autora aduce que no hay un único marco o matriz de normas, sino que estos son múltiples, distintos y contradictorios, lo que da más posibilidades de acción diferentes (2005:19).

En Los sentidos del sujeto, Butler vuelve a explicar esta interrelación con la metáfora del quiasmo ${ }^{15}$ : por un lado, los cuerpos no se pueden separar ni identificar al margen de las coordenadas lingüísticas y normativas que nos definen, delimitan y dan inteligibilidad; pero esto no supone que el cuerpo sea reductible o completamente modelable por el lenguaje y las normas; ya que la realidad material siempre excede y trasciende cualquier intento de delimitación, definición o normativización. Esto es, ni los marcos normativos ni los lingüísticos (ni, cabría añadir, los ejercicios epistemológicos escépticos y deconstructivos) llegan a abarcar completamente a los cuerpos, que no se pueden reducir al lenguaje y que escapan a los intentos de definición o de duda (2015:35). Por otro lado, la forma habitual (aunque no única) de conocer a los cuerpos (y otras realidades materiales) es con el lenguaje, los conceptos y categorías que nos ayudan a entender y definir lo que somos; por lo que el lenguaje afecta (no de modo unilateral ni necesario) a nuestra forma de ser. Por estos motivos, la pregunta de cómo o qué es un cuerpo al margen de estos marcos de inteligibilidad carece de respuesta porque cada cuerpo, desde el momento de su nacimiento, ya está definido y comprendido con el lenguaje, aunque siempre haya márgenes de error e indefinición. No se puede separar lenguaje y cuerpo de modo radical y tratar de entender, sin recurrir al lenguaje, qué sean los cuerpos. Sin embargo, el lenguaje también es inseparable de los humanos que lo hablan, que

${ }^{15}$ Butler da una definición más clara del quiasmo en las páginas 211 y siguientes de Los sentidos del sujeto, aunque más que un quiasmo (dos ejes que se cortan, formando una cruz) yo entendería esta interrelación como un bucle doble (como la imagen de las cadenas de ADN) donde dos elementos convergen, intersecan y se dan forma mutuamente, resultando inseparables (o más bien, la separación de estos polos dificultaría su comprensión). 
crean y modifican conceptos; por lo que también carece de sentido postular la existencia de una mente o lenguaje que, por separado, intente crear la realidad o dudar de ella (2015:35).

En conclusión, y según esta metáfora del quiasmo: los cuerpos y los lenguajes están interrelacionados y se influyen y afectan mutuamente, por lo que no es posible separarlos al modo escéptico o constructivista, ni tampoco primar una de estas realidades sobre la otra, como si pudiésemos prescindir del lenguaje y de los conceptos para enfrentarnos a la "pura" existencia material (lo que no sería comprensible) o como si pudiésemos prescindir de los cuerpos, dudar de ellos y de su existencia para vivir en la ficción de un lenguaje o mente inmaterial (lo que resulta invivible). Estas dos posibilidades resultan reduccionistas, incompletas y prácticamente ininteligibles si se acepta esta comprensión quiasmática de Butler $(2015: 36,56)$.

\subsection{Segunda escisión: en el interior de los sujetos}

\subsubsection{Críticas de Butler}

La segunda escisión que Butler encuentra en los planteamientos cartesianos y constructivistas es la que se da en el interior de los cuerpos, en el seno mismo del sujeto que teoriza, duda o deconstruye (2015:41). Es decir, de modo paralelo a la separación entre cuerpo y mundo, problematizada en la sección anterior, también se da una separación en el interior de cada sujeto que se escinde en dos ámbitos: el mental o conceptual que duda (res cogitans) y el corporal o material (res extensa) que es puesto en duda. Surgen conflictos y dificultades entre estos dos ámbitos, similares a los ya descritos, aunque más problemáticos porque se producen en el interior de los propios cuerpos.

Butler critica el dualismo irreconciliable que se da entre el cuerpo del sujeto que piensa y la idea que este sujeto tiene de sí mismo. De nuevo, el ámbito conceptual (la idea) prima sobre el material (el cuerpo) y trata de someterlo, deconstruirlo, modificarlo o incluso borrarlo para intentar acercarse, en la medida de lo posible, a la imagen especular o conceptual que el autor (en este caso, Descartes o Preciado) tiene de sí mismo (2015:43). Estos intentos son problemáticos porque intentan separar lo que según Butler y su comprensión quiasmática de la realidad viene unido, y por hacer primar de modo unilateral, monista y voluntarista el ámbito mental sobre el corporal. Además, como consecuencia de esta separación, surge una nueva comprensión de la identidad, espectral y cercana a la locura (2015:45). Doy ahora dos fragmentos donde se encuentran estas dificultades: 
(1) Descartes, en la soledad de su salón, quiere duda de todo, incluso de su propio cuerpo:

"Me consideraré a mí mismo como si no tuviera manos, ni ojos, ni carne, ni sangre, ni sentidos" (2005:87).

Aunque en un primer momento cree poder estar seguro de lo más inmediato y cercano, de estar:

"Aquí sentado cerca del fuego, en traje de casa, con este papel entre las manos" (2005:82).

En ese caso, tendría que admitir que su cuerpo, el que se calienta con el fuego y siente el tacto del batín, es real. Ya que si dudara de la realidad de su cuerpo estaría cerca de la locura:

“¿Cómo podré negar que estas manos y este cuerpo sean míos, si no es comparándome a ciertos insensatos cuyo cerebro está de tal modo turbado y ofuscado por los negros vapores de la locura que aseguran que son reyes, siendo pobres; que están vestidos de oro y púrpura, cuando están desnudos o que imaginan ser cántaros o tener el cuerpo de barro?" (2005:82).

Ahora bien, la duda hiperbólica reaparece, ya que Descartes se percata de que:

"Perfectamente puedo estar soñando o puede que un dios maligno me haga creer que tengo cuerpo" (2005:82).

La salida a esta duda es bien conocida: Descartes puede dudar de todo, incluso de la realidad de su propio cuerpo, pero no puede dudar de que es él mismo quien piensa, duda y se engaña:

"Me he procurado persuadirme de que nada había en el mundo, ni cielo, ni tierra, ni espíritus, ni cuerpos; ¿no me he persuadido, pues, de que yo no era? A pesar de todo, yo era sin duda, al persuadirme o al pensar alguna cosa. Mas no sé qué astuto o poderoso engañador emplea toda su industria en engañarme siempre. No hay, pues, duda en que soy si me engaña; y por mucho que me engañe, jamás podrá hacer que yo no sea, en tanto que yo piense que soy algo" (2005:89) [Énfasis de I.G.]. 
Y a partir de esa reflexión, reafirma su consabido cogito:

"Es preciso concluir [...] que esta proposición: yo soy, yo existo, es necesariamente verdadera, siempre que la pronuncio o la concibo en mi entendimiento" (2005:89) [Énfasis de I.G.].

(2) Preciado en su Testo Yonqui define una nueva época, el "capitalismo farmacopornográfico" en la que la realidad se difumina en un mundo virtual y psicotrópico. Ya no hay seres humanos sino:

"Subjetividades tóxico-pornográficas [...] que se definen por la sustancia (o sustancias) que dominan sus metabolismos, por las prótesis cibernéticas a través de las que se vuelven agentes, por los tipos de deseos farmacopornográficos que orientan sus acciones. Así hablamos de sujetos Prozac, sujetos cannabis, sujetos ritalina, sujetos cortisona, sujetos silicona, sujetos heterovaginales, sujetos doble penetración, sujetos Viagra" (2008:33).

"Las verdaderas materias primas del proceso productivo actual son la excitación, la erección, la eyaculación, el placer y el sentimiento de autocomplacencia y de control omnipotente. El verdadero motor del capitalismo actual es el control farmacopornográfico de la subjetividad, cuyos productos son la serotonina, la testosterona, los antiácidos, la cortisona, los antibióticos, el estradiol, el alcohol y el tabaco, la morfina, la insulina, la cocaína, el citrato de sidenofil (Viagra) y todo aquel complejo material-virtual que puede ayudar a la producción de estados mentales y psicosomáticos de excitación, relajación y descarga, de omnipotencia y de total control" (2008:3-37).

[El cuerpo] "es un sustrato de la fuerza orgásmica [que] no se reduce a un cuerpo pre-discursivo, ni tiene sus límites en la envoltura carnal que la piel bordea. [La] vida no puede entenderse como un sustrato biológico fuera de los entramados de producción y cultivo propios de la tecnociencia. [El] cuerpo es una entidad tecnovida multiconectada que incorpora la tecnología. Ni organismo ni máquina: tecnocuerpo" (2008:35).

Preciado también alude al "Manifiesto cíborg" de Haraway, explicado en la sección anterior, y lo traslada a la realidad de cada cuerpo, en concreto, al suyo propio: se autoadministra testosterona y comienza a escribir su Testo Yonqui. Como resultado, su cuerpo pasa a ser lo siguiente:

"Una prótesis molecular [añadida] a mi identidad transgénero low-tech hecha de dildos, textos e imágenes en movimiento" (2009:19). 
"No hablo con nadie, sólo escribo. Como si la escritura pudiera ser el único testigo fiable de este proceso" [...] "La cuarta noche no duermo. Estoy lúcida, enérgica, despierta [...] A las cuatro de la mañana sigo escribiendo sin un ápice de cansancio. Sentada frente al ordenador, siento los músculos de la espalda inervados por un cable cibernético que crece desde el suelo de la ciudad y sale por mi cabeza hasta engancharse en los planetas más alejados de la Tierra" (2008:48).

A partir de estos fragmentos, comenzaré a desgranar la crítica de Butler a la escisión que se da en la subjetividad de Descartes y Preciado cuando trasladan la duda hiperbólica y las tesis constructivistas a sus propios cuerpos (2015:41): por un lado está el "yo filósofo" o pensador (res cogitans) que teoriza y duda. Por otro lado, está el cuerpo o el "yo narrado y puesto en duda" que es, en principio, un cuerpo o realidad material (res extensa), que al ser dudado o alterado por sustancias externas comienza a tornarse problemático, no puede afirmarse a sí mismo ni confiar en sus sentidos o sensaciones y se entiende como un cuerpo ficticio, imaginado, espectral (2015:47).

Butler encuentra una contradicción, a la manera de una paralepsis (2014:42), en esta escisión del cuerpo que dificulta la propuesta de estos autores. Siguiendo un argumento clásico en el debate sobre el escepticismo, propuesto por George H. Moore (1972), Butler llama la atención sobre la paralepsis que comete Descartes, al negar (literariamente, con palabras) lo que afirma (literalmente, con gestos y actitudes). Lo que se intenta argumentar con palabras (la duda sobre el cuerpo) contradice lo que se declara con la voz y las acciones. Esto es difícil de sostener (y de entender) ya que Descartes y Preciado están escribiendo, con sus propias manos en un papel o en el ordenador y, al mismo tiempo, están intentando argumentar que su propio cuerpo, sus manos o sus ojos no son reales o no son tal y como pensábamos que eran. La argumentación se bloquea a sí misma, ya que para que la duda escéptica o el constructivismo tuviera éxito, estos autores deberían dejar de argumentar, o incluso tendrían que desaparecer, convertirse en algo bastante poco intuitivo como un ser pensante sin cuerpo o un tecnocuerpo prostético, hormonado e interconectado.

Otra dificultad de esta forma de argumentar es que el lenguaje se oscurece y hace complejo, lo que provoca una cierta ambigüedad (con la que juega el título de este artículo) y dificulta la comprensión de estas tesis escépticas y constructivistas. Se produce lo que Butler denomina una "gramática rara" que presenta una confusión semántica, cercana a lo contradictorio (2015:41). Esta confusión se debe a que estos autores intentan separar el sujeto tanto a un nivel gramatical, como a uno personal o subjetivo, de autoría (2015:42). Esto es, se duplica y se separa el sujeto gramatical de la argumentación (hay un yo que teoriza y un yo que es puesto en duda) y, al mismo tiempo, el autor que escribe 
(Descartes o Preciado) se duplica y se diferencia de la idea que tiene de sí mismo, acercándose a concepciones más ficticias que reales de la identidad, como la sustancia pensante sin cuerpo de Descartes o el "tecnocuerpo" o "identidad transgénero low-tech hecha de dildos, textos e imágenes en movimiento" en la que cree convertirse Preciado (2008:19). En casos como estos, el lenguaje se torna difícil de comprender, no se sabe bien quién está hablando y se producen frases extrañas, prácticamente ininteligibles, donde proliferan las dobles negaciones (por ejemplo: "Jamás podrá hacer que yo no sea, en tanto que yo piense que soy algo", Descartes, 2005:89) y aparecen nuevos términos de uso poco cotidiano (como "farmacopornográfico") que necesitan mucha explicación y contextualización para ser entendidos.

La tercera dificultad de esta escisión es que se acerca a la locura o esquizofrenia de un sujeto que ya no sabe qué es (Butler, 2015:42). Estos autores son conscientes del riesgo: Preciado lo asume y lo relaciona con la lucidez psicotrópica que le permite escribir (2008:48); mientras que Descartes sostiene que puede diferenciarse de los insensatos que creen estar vestidos cuando, en realidad, van desnudos por la calle gracias a la afirmación del cogito (2005:82). Butler analiza las dos respuestas que da Descartes para separarse de los casos de locura y concluye que no resultan satisfactorias.

En primer lugar, Descartes intenta afirmarse en su inmediatez más cercana y presente, espacial y temporalmente: se muestra seguro, no puede dudar de "que yo estoy aquí sentado cerca del fuego, en traje de casa, con este papel entre las manos"16 (2005:82). Butler no admite este argumento porque considera que pronombres como "yo" o "este" y adverbios como "aquí" y "ahora" son expresiones vacías que no poseen significado al margen del contexto de su enunciación (2015:40); pero lo que Descartes pretende hacer con su duda es separarse y prescindir de todo contexto, de su exterior, por lo que ya no puede decir "aquí" y "ahora". Esto es, no puede intentar diferenciarse de los casos de locura diciendo "yo estoy aquí", si al mismo tiempo está dudando de todo su exterior y de sí mismo, puesto que entonces ya ha vaciado de contenido estos términos referenciales. Además, quien crea ser un cántaro de barro también puede decir: "aquí y ahora, soy un cántaro". Esta objeción de Butler no es nueva, ya la mantuvo Russell en relación a los particulares egocéntricos (1997:97ss.) y el mismo Descartes conocía sus límites, al admitir que podía estar dormido y decir "aquí y ahora", por lo que no se libraría del engaño ni de la locura (2005:83).

En segundo lugar, para evitar caer en la locura, Descartes se reafirma en su cogito: puede dudar de todo, de estar cuerdo o loco, pero no puede dudar de que es él quien está dudando, por lo tanto, él existe (como algo inmaterial, mental

\footnotetext{
${ }^{16}$ Énfasis de I.G.
} 
y pensante); y se puede afirmar a sí mismo como "una cosa que duda, que entiende, que concibe, que afirma, que quiere, que no quiere, que imagina y que siente" $(2015: 93)^{17}$. Ahora bien, según Butler, Descartes puede afirmar su autoconciencia, pero no sabe lo que ésta es, ni tiene elementos para diferenciarla de la autoconciencia de quien crea estar vestido cuando está desnudo, ya que ha renunciado a su cuerpo y sentidos en la afirmación del pensamiento como única realidad; y en este ámbito mental vuelve a darse la posibilidad de engaño y locura. ¿Acaso no es posible que esta autoconciencia se engañe a sí misma o imagine ser algo que no es? Descartes cree superar la duda escéptica con la afirmación del cogito, pero al identificarse con una cosa inmaterial que piensa e imagina, reaparece la posibilidad de engaño, de error, de imaginar ser algo que no es (2015:43-44). Es decir, ¿por qué iba a ser más real alguien que imagina ser una mente pensante sin cuerpo que alguien que imagina ser un cántaro?

Butler concluye su crítica declarando que en su esfuerzo por establecer la certeza radical del yo, prescindiendo de todo para tratar de llegar a lo único seguro, Descartes se adentra en el terreno de la especulación y acaba identificándose con lo irracional, lo espectral y lo alucinatorio; eliminando toda certeza. En última instancia, y si se prescinde de la intervención divina en la tercera meditación, Descartes carece de argumentos para afirmar su existencia o diferenciarla de quien cree estar vestido cuando, en realidad, camina desnudo por las calles (2015:45). Como en los casos de "Matrix" y los cerebros en la cubeta, la duda escéptica persiste, pese a todo, porque la autoconciencia y el pensamiento en solitario no bastan para afirmar la realidad exterior.

En resumen, según Butler hay dos formas de entender el sujeto en la propuesta cartesiana (y por extensión, en la constructivista) pero ninguna de ellas es satisfactoria: o bien, el sujeto que duda sigue siendo corporal, físico y entonces, al formular la duda sobre su propia existencia, comete una paralepsis y confirma que existe aunque pretenda negarlo: o bien, el sujeto que duda y cree que puede prescindir de su cuerpo, de su realidad exterior, del lenguaje habitual y de todo lo conocido, se transforma en lo que Butler denomina una "espectralidad alucinatoria" que conlleva la "pérdida alucinatoria de la certeza del yo" (2015:43) y se acerca a casos de locura.

\subsubsection{Alternativas de Butler a estas dificultades y dimensión ética de su propuesta}

Para acabar de desgranar esta crítica y mostrar, de nuevo, las diferencias entre la propuesta de Butler y los planteamientos escépticos y constructivistas sólo queda destacar un elemento clave de la teoría butleriana que ya ha aparecido

\footnotetext{
${ }^{17}$ Énfasis de I.G.
} 
a lo largo de este artículo. Se trata de la dimensión social compartida por todos los humanos, de la precariedad y vulnerabilidad que nos caracteriza y nos hace depender de otras personas, por mucho que algunos autores pretendan negarlo, al perseguir lo que Butler denomina la concepción del "individualismo soberano" (2015:20) o la "ontología de la identidad discreta" (2010:54), propia de una filosofía muy individualista y de ciertas fantasías (sobre todo militares, añade la autora) que hacen creer que pueden darse sujetos y naciones completamente independientes, autónomas e invulnerables (2010:46).

Por el contrario, Butler incide en que hay que centrarse menos en estas concepciones individualistas y más en la precariedad que nos caracteriza a todos, especialmente porque las distribuciones diferenciales de esta precariedad causan que ciertas personas (o regiones) crean ser autónomas e independientes y ejerzan violencia con impunidad; mientras que otras sufren esta violencia sin ser reconocidas (2010:55). Ahora bien, para la autora, y a diferencia de los planteamientos escépticos y constructivistas (y dicho sea de paso, de la geopolítica actual de EEUU) las personas no nos podemos entender, ni tampoco sobrevivir, como entidades separadas y aisladas, sino que vivimos en conexión con otros, en un espacio y tiempo que no controlamos completamente y con cierta dependencia de las redes sociales y políticas en las que estamos insertos (2010:82-83).

Para sostener esta tesis, Butler propone un argumento que se puede entender como una reformulación, actualización y socialización de la prueba kantiana para refutar el idealismo (KRV B275-276) o del argumento del juego de lenguaje privado de Wittgenstein (1988 §256-271), según el cual: "Yo ya estoy en manos de otro cuando trato de plantearme quién soy" (Butler, 2010:83).

Es decir, según esta autora, los intentos de dudar de la realidad exterior y de otros humanos no son viables porque prescinden de elementos tan fundamentales y vitales como el contexto donde hemos crecido, los procesos de socialización, el aprendizaje de la lengua que nos permite expresar argumentos (escépticos o no), así como las redes de cuidados y el establecimiento de lazos con otras personas que nos han permitido sobrevivir. En oposición a la duda hiperbólica cartesiana y a los intentos posmodernos de deconstruir la realidad y la subjetividad, según este argumento de Butler, si podemos dudar de la realidad exterior y cuestionar si existimos o modificar ad libitum nuestros cuerpos es porque ya hemos sido criados en una comunidad, nos hemos relacionado con otros que nos han cuidado, mantenido y enseñado un lenguaje. Sólo posteriormente y en un terreno muy abstracto e individualista se puede cuestionar esta dimensión compartida y dudar de todo, pero entonces corremos el riesgo de perder el mundo, olvidarnos de los demás y su vulnerabilidad, de no reconocer la violencia que sufren las personas. A partir de ahí, y contrastando el cogito car- 
tesiano con ciertos contenidos de Malebranche, Butler concluye que "soy porque soy tocado" (2015:65).

Entonces, la duda escéptica y los planteamientos constructivistas se hacen más complicados e implausibles si se acepta esta concepción vulnerable e interrelacionada de los humanos, en vez de partir de la concepción individualista y solipsista, presente en las obras de Descartes, Haraway y Preciado ${ }^{18}$, donde desaparece cualquier vínculo o relación con el mundo exterior y otros humanos.

Michael Williams también ha criticado al escepticismo cartesiano por su desapego y separación (detachment) de la realidad exterior y los humanos que facilita la duda hiperbólica (1988:426). Wittgenstein mantuvo una consideración similar al destacar que era difícil (o incluso siniestro) creer que los humanos de nuestro alrededor son autómatas sin conciencia. Esto se puede hacer en soledad, en una habitación pero es mucho más difícil cuando se está en contacto con la gente, por ejemplo, en la calle (1988 §420). Al salir de la soledad del gabinete, la duda escéptica sobre la realidad del mundo exterior y los humanos se torna cada vez más rarefacta e implausible y las pruebas que reforzaban los argumentos escépticos (el no poder distinguir si estamos dormidos o despiertos, en la realidad o en un mundo virtual) se debilitan si las aplicamos a un grupo de personas, sus experiencias, contrastes y desacuerdos, en vez de a un sujeto aislado y solo. En resumen, las dudas escépticas son más difíciles de sostener si en vez de formularse en la primera persona del singular de alguien que piensa en solitario, se hacen en la primera persona del plural, de una alguien que reconoce sus vínculos, dependencias y relaciones con otros.

Para cerrar esta línea de argumentación quisiera aducir que las críticas de Butler en oposición al escepticismo y al constructivismo no se deben sólo a consideraciones epistémicas, sino que están movidas por una preocupación, práctica, ética y real, acerca del reconocimiento de las vidas humanas. Es decir, de modo similar la comprensión cavelliana del escepticismo como el drama del no reconocimiento de los demás (1970:370ss.), Butler cuestiona los argumentos escépticos clásicos y las posiciones constructivistas porque estas dos formas de entender a los humanos (como seres independientes, solitarios, adultos, voluntaristas, separados del exterior y de los demás) no tienen en cuenta una dimensión inherente e ineliminable de la humanidad: la vulnerabilidad y la pre-

${ }^{18}$ Para tratar con justicia la obra de Preciado, cabe destacar que sí tiene en cuenta esta dimensión intersubjetiva de las relaciones humanas (que sobre todo identifica con intercambios sexuales), sin embargo, mantiene la plasticidad y mutabilidad de los cuerpos humanos (en soledad o en grupo), gracias a las sustancias y prótesis ya aludidas. Si se quiere profundizar en este tema, véase el capítulo quinto de Testo Yonqui donde relata sus encuentros sexuales con Virginia Despentes, que pasa a ser otro cuerpo más, en proceso de experimentación y cambio. Ahora bien, la vertiente ética de la propuesta butleriana no aparece en la obra de Preciado. 
cariedad. Es decir, en estos argumentos no se considera que todos hemos sido dependientes o hemos necesitado ayuda de otros en algún momento de nuestras vidas y que seguimos siendo vulnerables $(2006: 71 ; 2010: 30,46)$. Este reconocimiento de la vulnerabilidad y la precariedad concede una dimensión ética a la propuesta de Butler, referida a la responsabilidad que tenemos hacia otros humanos (idealmente hacia todos) y que incluye un cierto imperativo moral, que contempla la obligación que todos deberíamos tener de reconocer a los demás, evitar dañarlos e intentar, en la medida de lo posible, reducir la precariedad y la vulnerabilidad; aun sabiendo que nunca se logrará eliminar estas características por ser intrínsecas a la especie humana $(2010: 43,57)$.

Entonces, según esta propuesta de Butler, las posiciones escépticas que dudan sobre el mundo exterior y otros seres humanos, así como las posturas constructivistas centradas en el sujeto, su cuerpo y sus deseos sólo resultan posibles porque olvidan esta dimensión compartida, vulnerable y codependiente de la especie humana y aspiran, por el contrario, al individualismo soberano y neoliberal ya criticado. Su argumentación supera el ámbito epistémico y se vincula con la dimensión ética del reconocimiento, ya que no tener en cuenta la precariedad puede dar lugar a que la violencia que reciben los seres humanos no sea reconocida, criticada ni evitada (2010:79).

\section{ADENDA}

Para acabar, quisiera dar una última explicación que considero necesaria para que las críticas expuestas en el artículo no se entiendan como dogmáticas o categóricas. En ningún momento he pretendido negar la posibilidad de mantener una duda escéptica o una postura constructivista moderada, sino que considero necesario (y sano) contextualizar y dar una razón de ser a estas posturas para evitar que se hagan hiperbólicas, se intenten aplicar a toda la realidad o se distancien de circunstancias reales y preocupantes para los humanos. En este sentido, cabe recordar que Wittgenstein mantuvo que las dudas sobre la existencia sólo tienen lugar en un juego de lenguaje (1993:§24) y que las dudas deben tener una razón (1993:§4). La posibilidad del juego de lenguaje es que no se ponga en duda todo aquello de lo que puede dudarse (1993:§392), sino que se han de mantener ciertas certezas o ejes (1993:§152), a partir de los cuales se puedan articular dudas.

Es decir, es posible imaginar escenarios concretos donde tiene sentido formular una duda escéptica; el ejemplo clásico de Wittgenstein es el de una persona que despierta en la cama de un hospital, con las manos vendadas y no recuerda qué le ha sucedido. En este caso, expresiones como "no sé si tengo manos" o "dudo de si tengo manos" tendrían sentido (1993:§23), causarían ansiedad (elemento ob- 
viado por los autores escépticos) y se solucionarían con el tiempo. Otro ejemplo es el de alguien que inicia una conversación por Internet y puede dudar de que la persona que dice estar al otro lado sea quien dice que es o, incluso, que sea una persona, ya que puede ser un ordenador programado para responder como si fuera humano ${ }^{19}$. Se necesitan entonces corroboraciones externas para confirmar la identidad o existencia de esta persona (plantear paradojas que un ordenador no podría resolver, pedir pruebas de identidad, consultar con otros usuarios o con la policía...). De nuevo, a partir de una duda, plausible y contextualizada, se desprende la realidad de otros elementos y personas, por lo que esta duda no se puede totalizar o aplicar a toda la realidad (ni real, ni virtual). También existen casos de personas diagnosticadas con esquizofrenia que no pueden estar seguros de si los seres humanos de su alrededor son reales, como le sucedía a John $\mathrm{Nash}^{20}$. Sin embargo, una vez fue consciente de su enfermedad, Nash preguntaba a las personas de su alrededor (especialmente a las de confianza) si también veían a esas otras personas o si las estaba imaginando él; y aquí vuelve a aparecer una duda escéptica plausible que se solventa en el establecimiento de redes de confianza con los demás. Por extensión, entiendo que ciertas prácticas performativas y deconstructivas son necesarias en casos concretos, por ejemplo para denunciar la patologización de personas trans o las discriminaciones a personas LGTBI y lograr que más personas puedan tener los mismos derechos, y Butler estaría de acuerdo con estas prácticas. Sin embargo, totalizar esta idea y aducir que todos somos cíborgs (Haraway) o productos de la industria farmacopornográfica (Preciado) resulta excesivo. Y retomando el concepto de precariedad de Butler, cabe aducir que estas prácticas performativas y deconstructivas se dan sobre todo en un ámbito occidental, bastante privilegiado, donde ya se han solucionado los temas relativos a la precariedad y vulnerabilidad.

Es decir, ciertas dudas escépticas o constructivistas moderadas resultan posibles en un contexto concreto y con una justificación, los problemas comienzan a surgir cuando estas dudas se dan sin razones aparentes y se intentan trasladar a la totalidad de los objetos físicos (Wittgenstein, 1993:§35) o a toda la humanidad. En esos casos, se puede llegar a bloquear el conocimiento y las relaciones humanas, algunas personas, su vulnerabilidad y precariedad, pueden ser invisibilizadas y esto puede causar mucho daño a estas vidas más precarias y menos reconocidas.

Concluyo este artículo insistiendo en la dimensión ética y política de la propuesta de Butler, que a partir del reconocimiento de las vidas precarias y su vul-

\footnotetext{
${ }^{19}$ Esto no deja de ser una variante del Test de Turing.

${ }^{20}$ Véase la biografía de Nash en la Wikipedia (https://es.wikipedia.org/wiki/John_Forbes_Nash) y existe una película inspirada en su vida: "Una mente maravillosa" (Howard, 2001).
} 
nerabilidad critica posicionamientos teóricos abstractos y solipsistas como los escepticismos y constructivismos que, al totalizarse, corren el riesgo de olvidar esta dimensión vulnerable y compartida. Su crítica supera el ámbito de la epistemología y se traslada a la ética y la política; hace un llamamiento a nuestra responsabilidad con todas las personas, para reconocer nuestra interdependencia y la condición generalizada de la precariedad humana y actuar en consecuencia (2010:77). Por tanto, Butler no se puede entender como una autora posmoderna o constructivista que niegue o dude de la existencia humana.

\section{BIBLIOGRAFÍA}

Benhabib, Seyla (1992) El ser y el otro en la ética contemporánea. Barcelona: Gedisa.

Benhabib, Seyla (et al) (1995) Feminist Contentions. New York, London: Routledge.

Bostrom, Nick (2003) “Are you living in a computer simulation?", Philosophical Quarterly Vol. 53 (pp. 243-255).

Boucher, Geoff (2006) "The Politics of Performativity", Parrhesia, Vol. 1 (pp. 112 - 141).

Burgos, Elvira (2008) ¿Qué cuenta como una vida? La pregunta por la libertad en Judith Butler. Madrid: Antonio Machado Libros.

Butler, Judith (1990) El género en disputa. Barcelona: Paidós.

Butler, Judith (2005) Dar cuenta de sí mismo. Madrid: Amorrortu.

Butler, Judith (2006) Vidas Precarias. Madrid: Amorrortu.

Butler, Judith (2010) Marcos de guerra. Barcelona: Paidós.

Butler, Judith (2015) Los sentidos del sujeto. Barcelona: Herder.

Cavell, Stanley. (1979) The Claim of Reason. Oxford: Oxford UP.

Chakravartty, Anjan, "Scientific Realism", The Stanford Encyclopedia of Philosophy (Fall 2015 Edition), Edward N. Zalta (ed.) http://plato.stanford.edu/archives/ fall2015/entries/scientific-realism/.

Descartes, René (2005) Meditaciones Metafisicas. Madrid: Alianza Editorial (Edición de Jesús Díaz).

Gilmore, Anthony (1932) “The Affair of the Brains”, Astounding Stories (March 1932).

Haraway, Donna (2005) “Manifiesto Cíborg”, Ciencia, cíborgs y mujeres. Madrid: Cátedra.

Harman, Gilbert (1973) Thought. Princeton: Princeton University Press.

Kant, Inmanuel (1975) Crítica de la razón pura. Madrid: Alfaguara.

Klein, Peter, "Skepticism", The Stanford Encyclopedia of Philosophy (Summer 2015 Edition), Edward N. Zalta (ed.) http://plato.stanford.edu/archives/sum2015/entries/ skepticism. 
Moore, George E. (1972) Defensa del sentido común y otros ensayos. Madrid: Taurus.

Moravec, Hans (1999) "Simulation, Consciousness, Existence”, Intercommunication Vol. 28 (pp. 98-112).

Nussbaum, Martha (1999) "The Professor of Parody", The New Republic. 22/02/1999.

Pérez Navarro, Pablo (2008) Del texto al sexo. Judith Butler y la performatividad. Egales: Barcelona.

Preciado, Beatriz/Paul (2008) Testo Yonqui. Madrid: Espasa.

Preciado, Beatriz/Paul (2011) Manifiesto Contrasexual. Barcelona: Anagrama.

Putnam, Hilary (1981) Reason, Truth, History. Cambridge: Cambridge UP.

Russell, Bertrand (1977) El conocimiento humano. Madrid: Taurus.

Soley Beltrán, Patricia y Sabsay, Leticia (2012) (eds.) Judith Butler en disputa. Egales: Barcelona.

Stroud, Barry (1985) The Significance of Philosophical Scepticism. Oxford: Clarendon Press.

Unger, Peter (1993) “Scepticism and Certainty”, Williams, Michael (1993) Scepticism. Aldershot: Dartmouth.

Williams, Michael (1988) “Epistemological Realism and the Basis of Scepticism”, Mind. New Series, Vol. 97, N. 387. (Jul., 1988) (pp. 415-439).

Wittgenstein, Ludwig (1988) Investigaciones filosóficas. Barcelona: Crítica.

Wittgenstein, Ludwig (1993) Sobre la certeza. Barcelona: Gedisa.

Páginas web consultadas:

BBC Earth: "We might live in a computer program but it may not matter" http://www.bbc.com/earth/story/20160901-we-might-live-in-a-computer-programbut-it-may-not-matter [Última consulta: 10/03/2017].

Enciclopedia Stanford de Filosofia http://plato.stanford.edu/ Dos entradas: "Skepticism" y "Scientific realism" [Última consulta: 10/03/2017].

“John Nash” en Wikipedia: https://es.wikipedia.org/wiki/John_Forbes_Nash [Última consulta: 10/03/2017].

\section{Películas citadas:}

"Código Fuente" (Source Code), Duncan Jones, EEUU, 2011.

"Matrix" (The Matrix), Lana y Lilly Wachowski, EEUU, 1999.

“Origen” (Inception), Christopher Nolan, EEUU, 2010.

"Una mente maravillosa" (A Beautiful Mind) Ron Howard, EEUU, 2001. 